\title{
MANY HANDS MAKE WORK LIGHT OR NOT? A NOVEL TOOL FOR GROUP DECISION MAKING WITH ANP
}

\author{
Elena Rokou \\ School of Mechanical Engineering \\ National Technical University of Athens \\ Athens, Greece \\ E-mail: erokou@mail.ntua.gr
}

\begin{abstract}
Although every problem has multiple solutions, many restrictions and various ways to be addressed, there are also many techniques, methods and approaches proposed by scholars and practitioners that can be implemented to help increase our decision making effectiveness. The Forum will address this issue by engaging participants to reach a group decision using a new tool in the form of a Microsoft Excel Add-In that supports the Group Analytic Network Process (GANP) and it is integrated with the Super Decisions software. An illustrative case concerning the decision of a city council on how to use a community lot based on given alternatives (among a new parking lot, a hospital and sustainable landfill) and preselected criteria will be used during the Forum. The results of this game will provide significant insights for the group decision making process, explore the proposed techniques and bring out the advantages and disadvantages reported in literature.
\end{abstract}

Keywords: ANP, MCDA, Software tool, SuperDecisions, Group Decision Making

\section{Introduction}

The advantages of group's decisions over individual's have been widely studied in literature. Group decision making makes the most of the combined individual abilities, knowledge and expertise of the group members. It leads to greater group commitment to the results of the decision making process since the decision makers share the responsibility. When deciding as a group, biased opinions and restricted perspectives cannot easily prevail. Being in a group also tends to motivate and inspire group members by enhancing their level of contribution.

Every group decision making process can be roughly split in three phases, the first concerns the problem modeling while the second one is about finding out which is the preferred solution among several alternatives with respect to a set of criteria and the third one refers to the elaboration of the collected data/judgments to calculate the priorities. The actual group decision making process can either be synchronous, e.g. we have all the decision makers in a room and they try to make the decision on the spot; or asynchronous, for example using online questionnaires. However, the calculation steps are usually done afterwards and then the results are communicated to the stakeholders.

\section{Literature Review}

\subsection{Group Decision Making}

The advantages of group's decisions over individual's (Alonso, Herrera-Viedma, Chiclana, \& Herrera, 2010; Basak \& Saaty; Bonner, 2004; Bonner, Baumann, \& Dalal, 2002; Boroushaki \& Malczewski, 2010; 
Lago et al., 2007; Thomas L. Saaty \& Shang, 2007; Thomas L. Saaty \& Vargas, 2007; Saunders \& Miranda, 1998) have been widely studied in literature. Group decision making makes the most of the combined individual abilities, knowledge and expertise of the group members. It leads to greater group commitment to the results of the decision making process since they share the responsibility. When deciding as a group, biased opinions and restricted perspectives cannot easily prevail. Being in a group also tends to motivate and inspire group members by enhancing their level of contribution. On the other hand, there are several potential disadvantages of group decision making. For example, sometimes group members feel pressure to conform to what seems to be the dominant view in the group, known as groupthink. Another disadvantage of group decision making is group polarization that is the tendency of a group to converge on extreme solutions to a problem. Another drawback of group decision making is that the status of the group member that proposes an alternative or idea influences the reactions and acceptability level of the idea itself. Furthermore, decision making is more time consuming and costly than the process of individual decision making since there are many opinions to be considered and valued. In order to have an efficient and effective decision making process, it should be properly structured.

To support the above process Group Decision Support Systems (GDSSs) are used. A GDSS is an interactive computer-based system that facilitates the solution of problems by a group of decision makers which work together as a team (Kraemer \& King, 1988). This can be achieved by removing communication barriers, providing procedures for structuring decision analysis and conducting the pattern, timing and content of the discussion in a systematic manner (DeSanctis \& Gallupe, 1987). Furthermore, studies have shown that a GDSS may establish a level of anonymity and loose internal structure in group decision that can favorably affect and enhance contribution of each group member no matter if the group is multicultural or homogeneous. Another positive about using GDSS is that it facilitates information access during all step of the decision process.

During the herein described Forum, attendees will be given a specific human resources decision problem and they will be step by step assisted in using a Multi Criteria Decision Support (MCDA) technique, namely Group ANP, to make a group decision. The employed method is briefly described in the following section.

\subsection{Group ANP}

The Analytic Network Process (ANP) is a MCDA approach developed by Thomas Saaty in 1996 (T. L. Saaty, 1996). It is a theory of relative measurement on absolute scales of both tangible and intangible criteria, called elements and their classification in groups, clusters, based on their commonalities. Input data comprise of the judgments of expert decision makers and qualitative/quantitative criteria. The model components are clusters and elements that have interdependent relationships and incorporate feedback. Thus, ANP achieves an accurate representation of real life problems especially in cases where there is a high degree of risk and uncertainty. Technically, the ANP method provides an algorithm for the homogenization of judgments used to compute the relative priorities of the model components. This way relative importance among criteria and clusters that influence the decision is presented (Kirytopoulos, Voulgaridou, \& Rokou, 2011).

A framework for group decision using the ANP method was initially proposed by Saaty and Shang (2007) in order to provide a method that brings about consensus and at the same time prevents one person from dominating a meeting. In this section the algorithm of group ANP is briefly presented:

$\mathbf{1}^{\text {st }}$ step: Development of an ANP model that describes the problem to be solved. This step includes the analysis and modelling of the problem, the identification of alternatives and criteria and their classification in clusters. 
IJAHP Article: Mu, Saaty/A Style Guide for Papers Submitted to the International Journal of the Analytic Hierarchy Process

$\mathbf{2}^{\text {nd }}$ step: The paths of influence among the elements should be described. This step leads to the creation of a network containing all the decision elements and their inner (within the same cluster) and outer relationships (among elements of different clusters).

$\mathbf{3}^{\text {rd }}$ step: This step is slightly different from the corresponding in standard ANP. In group ANP we have a group of decision makers that each one gives his/her judgments independently, instead of having just one decision maker.

$4^{\text {th }}$ step: Taking as granted that each decision maker's individual set of judgments is within an acceptable level of consistency, all judgments are combined using an aggregation function to generate the Supermatrix and the Cluster matrix.

$5^{\text {th }}$ step: The Supermatrix is weighted by the Cluster matrix and thus transformed to the column stochastic Weighted Supermatrix.

$6^{\text {th }}$ step: The Weighted Supermatrix is limited by raising it to a sufficiently large power until it converges into a stable limit matrix. In the end, the weights of criteria and alternatives will lead to the final priorities.

\section{Hypotheses/Objectives}

The idea is to interactively explore whether "many hands make work light or not?" by showing how group decision making with ANP can be effectively used in practice to get quicker to a group decision that really reflects the groups dynamic.

The Forum will address this issue by engaging participants to reach a group decision using ANP, a multicriteria decision analysis (MCDA) technique (Saaty, 1996). For this purpose, a proprietary Microsoft Excel Add In, called Group Super Decisions for Excel (GSDE), that implements the Group Analytic Network Process (GANP) and provides importing/exporting of Super Decisions models, will be used. This software tool will provide the means for generating an ANP model using Super Decisions and exporting the model to the Excel Add In as an Excel Sheet based Questionnaire. This Excel based questionnaire can either be used as a basis to generate $\mathrm{x}$ Excel sheet questionnaires to give to the decision makers or use an external tool to gather the judgments and either pass each set of judgments to the corresponding sheet or pass the aggregated values to the corresponding total sheet or even give the initial Supermatrix as it was generated by some other external tool. In the case that the Excel is used as the main tool for the GANP then the entered judgments will be reviewed and in case of major inconsistencies, the decision makers will be asked to reevaluate their position, till an accepted level of consistency is reached. At that point, the given judgments will be aggregated and the group preferences will be exported back to Super Decisions to have the priorities calculated and work with the model as usual.

As all participants should be equally familiar, the illustrative case that will be used during the Forum concerns the selection of lot based on given alternatives: a new parking lot, a hospital and sustainable landfill along with a short description of the pros and cons of each option. The problem's model and thus the available alternatives, selection criteria and relationships will be given. The results of this game will provide significant insights for the group decision making process dynamics, especially at the operations level, keeping in mind that we want to achieve a better perception of how to effectively use the existing tools in order to perform group decision making using ANP. 
IJAHP Article: Mu, Saaty/A Style Guide for Papers Submitted to the International Journal of the Analytic Hierarchy Process

\section{Research Design/Methodology}

The group decision making process that will be followed is depicted in Figure 2 and analyzed hereafter.

\section{Creation of groups of decision makers}

Import Model to GSDE

Generate questionnaires

Aggregate judgments

\section{Preview Super Matrix}

Figure 2 Group decision making process

Initially, according to the number of attendees groups of decision makers will be formed and a member of each group will get the role of the facilitator. Those that have previously taken part in a similar decision will join the same group and will be considered as 'experts'. Then a model previously created in Super Decisions (http://www.superdecisions.com/) will be imported to GSDE and each group's facilitator will create his/her session and ask his/her group members to join it as shown in Figure 3.

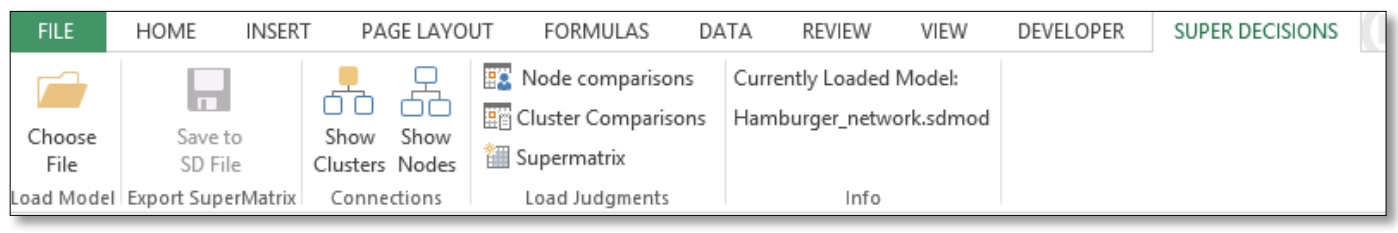

Figure 3 GSDE Add In

Following, each decision maker will input his/her judgments, check for inconsistencies in the inserted values and accordingly adjust their judgments. The first part of the process is completed when all group members have submitted their judgments, as shown in Figures 4 and 5. 
IJAHP Article: Mu, Saaty/A Style Guide for Papers Submitted to the International Journal of the Analytic Hierarchy Process

\begin{tabular}{|c|c|c|c|c|c|c|c|c|}
\hline \multirow{2}{*}{$\frac{4}{1}$} & \multirow[t]{2}{*}{ c } & \multirow[t]{2}{*}{ D } & \multicolumn{4}{|c|}{$\mathrm{EFGH} \mathrm{F}$. } & \multicolumn{2}{|c|}{$\mathrm{K} \underline{\mathrm{L}} \mathrm{M}$} \\
\hline & & & & & & & & \\
\hline 2 & Judge the & Alternatives & & & & & & \\
\hline 3 & For aesthetics & choose the most preferred alternative: & & & & & & \\
\hline 4 & ㅁ & Bridge $\mathrm{A}$ & & & & & & \\
\hline 5 & ㅁ & Bridge $B$ & & & & & & \\
\hline 6 & & & & & 345 & 56 & & 89 \\
\hline 7 & & & & $\square \square$ & $\square \square \square$ & $\square \square$ & ㅁ & $\square \square$ \\
\hline 8 & For safety & choose the most preferred alternative: & & & & & & \\
\hline 9 & ㅁ & Bridge A & & & & & & \\
\hline 10 & ㅁ & Bridge B & & & & & & \\
\hline 11 & & & & 2 & 345 & 56 & & 89 \\
\hline 12 & & & & $\square \square$ & $\square \square \square$ & $\square \square$ & & 므 \\
\hline 13 & Judge the & Objectives & & & & & & \\
\hline 14 & For bridge $\mathrm{A}$ & choose the most important objective & & & & & & \\
\hline 15 & ㅁ. & aesthetics & & & & & & \\
\hline 16 & 만 & safety & & & & & & \\
\hline 17 & & & & & 345 & 56 & & 89 \\
\hline 18 & & & & $\square \square$ & 므 & 므 & ㅁ & 므 \\
\hline 19 & For bridge $\mathrm{B}$ & choose the most important objective & & & & & & \\
\hline 20 & ㅁ. & aesthetics & & & & & & \\
\hline 21 & 문 & safety & & & & & & \\
\hline 22 & & & & 2 & 345 & 56 & & 89 \\
\hline 23 & & & & & ㅁㅁ & ㅁ & ㅁ & $\square \square$ \\
\hline
\end{tabular}

Figure4 Group ANP Questionnaire

\begin{tabular}{|c|c|c|c|}
\hline A & B & C & D \\
\hline \multicolumn{4}{|l|}{1 Alternatives } \\
\hline \multicolumn{4}{|l|}{1 McDonalds } \\
\hline & 1 McDonalds & 2 Burger King & 3 Wendys \\
\hline 1 McDonalds & 1.0000 & . 5.0000 & $\ldots$ \\
\hline 2 Burger King & $=0.0000$ & 1.0000 & 4.0000 \\
\hline 3 Wendys & 0.0000 & 0.2500 & 1.0000 \\
\hline \multicolumn{4}{|l|}{2 Burger King } \\
\hline & 1 McDonalds & 2 Burger King & 3 Wendys \\
\hline 1 McDonalds & 1.0000 & 0.0000 & 5.0000 \\
\hline 2 Burger King & $=0.0000$ & 1.0000 & $==-0,0000$ \\
\hline 3 Wendys & 0.2000 & t. 0000 & 10000 \\
\hline \multicolumn{4}{|l|}{3 Wendys } \\
\hline & 1 McDonalds & 2 Burger King & 3 Wendys \\
\hline 1 McDonalds & 1.0000 & 3.0000 & $=0.000$ \\
\hline 2 Burger King & 0.3333 & 1.0000 & y.no00 \\
\hline 3 Wendys & 0.0000 & 6.0000 & 1.0000 \\
\hline
\end{tabular}

Figure5 Entering Judgments

During the second phase of the process, the facilitator will check for group inconsistencies and if needed ask for corrective actions. Finally, the facilitator closes the session by requesting the computation of the 
IJAHP Article: Mu, Saaty/A Style Guide for Papers Submitted to the International Journal of the Analytic Hierarchy Process

final group results and makes those results available to all group members by exporting them to Super Decisions. The last step is done using SuperDecisions, where the sensitivity analysis takes place.

\begin{tabular}{|c|c|c|c|c|c|c|c|c|c|c|}
\hline & & \multirow{2}{*}{\begin{tabular}{|l|}
1 Alternatives \\
1 McDonalds \\
\end{tabular}} & \multirow{2}{*}{2 Burger King } & \multirow{2}{*}{3 Wendys } & \multirow{2}{*}{\begin{tabular}{|l|}
2 Advertising \\
1 Creativity \\
\end{tabular}} & \multirow{2}{*}{\begin{tabular}{|l|} 
\\
2 Promotion \\
\end{tabular}} & \multirow[b]{2}{*}{3 Frequency } & \multicolumn{2}{|l|}{3 Quality of Food } & \multirow[b]{2}{*}{3 Portion } \\
\hline & & & & & & & & 1 Nutrition & 2 Taste & \\
\hline \multirow[t]{3}{*}{1 Alternatives } & 1 McDonalds & 0 & 0.833333 & 0.75 & 0.614067 & 0.717376 & 0.717376 & 0.248829 & 0.29 & 0.59891 \\
\hline & 2 Burger King & 0.8 & 0 & 0.25 & 0.268517 & 0.194204 & 0.194204 & 0.156062 & 0.104 & 0.12619 \\
\hline & 3 Wendys & 0.2 & 0.166667 & 0 & 0.117416 & 0.08842 & 0.08842 & 0.595109 & 0.606 & 0.27491 \\
\hline \multirow[t]{3}{*}{2 Advertising } & 1 Creativity & 0.207398 & 0.178337 & 0.281 & 0 & 0.333333 & 0.5 & 0 & 0 & 0 \\
\hline & 2 Promotion & 0.129793 & 0.112048 & 0.07197 & 0.125 & 0 & 0.5 & 0 & 0 & 0 \\
\hline & 3 Frequency & 0.662809 & 0.709615 & 0.64703 & 0.875 & 0.666667 & 0 & 0 & 0 & 0 \\
\hline \multirow[t]{3}{*}{3 Quality of Food } & 1 Nutrition & 0.331945 & 0.281003 & 0.62411 & 0 & 0 & 0 & 0 & 0 & 0 \\
\hline & 2 Taste & 0.138794 & 0.071972 & 0.28227 & 0 & 0 & 0 & 0 & 0 & 0 \\
\hline & 3 Portion & 0.529261 & 0.647026 & 0.09362 & 0 & 0 & 0 & 0 & 0 & 0 \\
\hline \multirow[t]{8}{*}{4 Other } & 1 Price & 0.032858 & 0.240824 & 0.02998 & 0 & 0.833333 & 0 & 0 & 0 & 0.85714 \\
\hline & 2 Location & 0.106315 & 0.2231 & 0.14175 & 0.709478 & 0 & 0.1958 & 0 & 0 & 0 \\
\hline & 3 Service & 0.023726 & 0.141824 & 0.06482 & 0 & 0 & 0 & 0 & 0 & 0 \\
\hline & 4 Speed & 0.048295 & 0.140657 & 0.06412 & 0 & 0 & 0 & 0 & 0 & 0 \\
\hline & 5 Cleanlines & 0.332769 & 0.10956 & 0.27559 & 0 & 0 & 0 & 0 & 0 & 0 \\
\hline & 6 Menu Item & 0.159308 & 0.051165 & 0.15708 & 0.137685 & 0.166667 & 0.310814 & 0 & 0 & 0 \\
\hline & 7 Takeout & 0.073562 & 0.050637 & 0.05891 & 0 & 0 & 0 & 0 & 0 & 0.14286 \\
\hline & 8 Reputation & 0.223167 & 0.042234 & 0.20776 & 0.152837 & 0 & 0.493386 & 0 & 0 & 0 \\
\hline
\end{tabular}

Figure6 Supermatrix to be exported to SuperDecisions

\section{Conclusion-Learning points}

A final conclusion will be derived and the main learning points concerning both the group decision process and the method used will be clarified. Among completion of the session the attendees will have learned tips and tricks for group decision making and acquired basic understanding for using the Group ANP method and the appropriate tools to take group decisions.

\section{Key References}

Alonso, S., Herrera-Viedma, E., Chiclana, F., \& Herrera, F. (2010). A web based consensus support system for group decision making problems and incomplete preferences. Information Sciences, 180(23), 4477-4495. doi: DOI: 10.1016/j.ins.2010.08.005

Basak, Indrani, \& Saaty, Thomas. Group decision making using the analytic hierarchy process. Mathematical and Computer Modelling, 17(4-5), 101-109. doi: Doi: 10.1016/0895-7177(93)90179-3

Bonner, Bryan L. (2004). Expertise in Group Problem Solving: Recognition, Social Combination, and Performance. Group Dynamics, 8(4), 277-290.

Bonner, Bryan L., Baumann, Michael R., \& Dalal, Reeshad S. (2002). The effects of member expertise on group decision-making and performance. Organizational Behavior and Human Decision Processes, 88(2), 719-736. doi: Doi: 10.1016/s0749-5978(02)00010-9

Boroushaki, Soheil, \& Malczewski, Jacek. (2010). Measuring consensus for collaborative decisionmaking: A GIS-based approach. Computers, Environment and Urban Systems, 34(4), 322-332. doi: DOI: 10.1016/j.compenvurbsys.2010.02.006

DeSanctis, G., \& Gallupe, R.B. (1987). A foundation for the study of group decision support systems. Manage Sci, 33(5), 589-609.

Kirytopoulos, K., Voulgaridou, D. , \& Rokou, E. 2011. (2011). 'ANP SOLVER, an alternative tool for implementing the ANP method'. International Journal of Applied Decision Sciences (IJADS).

Kraemer, Kenneth L., \& King, John Leslie. (1988). Computer-based systems for cooperative work and group decision making. ACM Comput. Surv., 20(2), 115-146. doi: http://doi.acm.org/10.1145/46157.46158

Lago, Pilar Pazos, Beruvides, Mario G., Jian, Jiun-Yin, Canto, Ana Maria, Sandoval, Angela, \& Taraban, Roman. (2007). Structuring group decision making in a web-based environment by using the nominal 
IJAHP Article: Mu, Saaty/A Style Guide for Papers Submitted to the International Journal of the Analytic Hierarchy Process

group technique. Computers \& Industrial Engineering, 52(2), 277-295. doi: DOI: 10.1016/j.cie.2006.11.003

Saaty, T. L. (1996). Decision making with dependence and feedback: the analytic network process. Pittsburgh: RWS Publications.

Saaty, Thomas L., \& Shang, Jen S. (2007). Group decision-making: Head-count versus intensity of preference. Socio-Economic Planning Sciences, 41(1), 22-37. doi: DOI: 10.1016/j.seps.2005.10.001

Saaty, Thomas L., \& Vargas, Luis G. (2007). Dispersion of group judgments. Mathematical and Computer Modelling, 46(7-8), 918-925. doi: DOI: 10.1016/j.mcm.2007.03.004

Saunders, Carol, \& Miranda, Shaila. (1998). Information acquisition in group decision making. Information \& Management, 34(2), 55-74. doi: Doi: 10.1016/s0378-7206(98)00036-6 